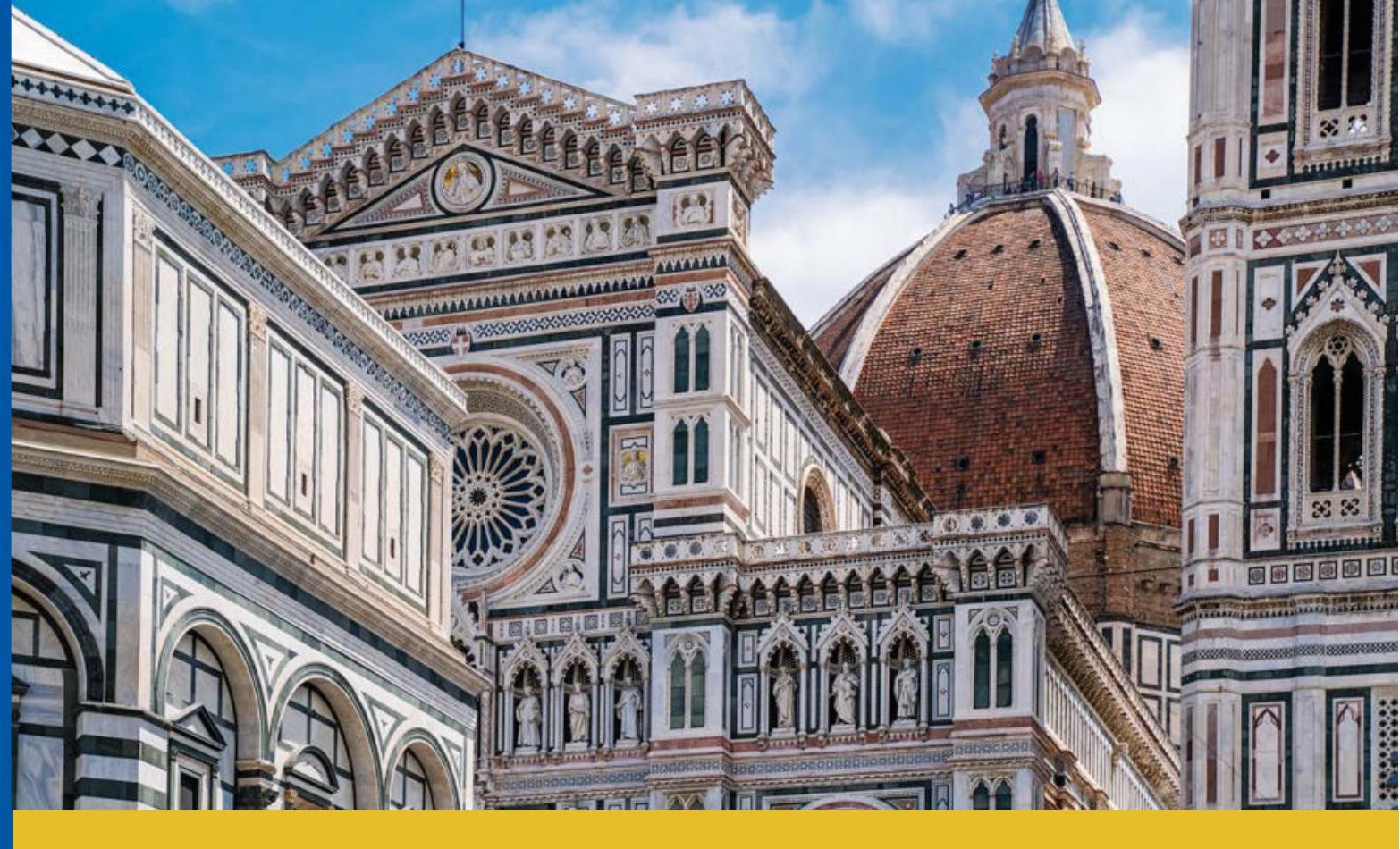

\title{
ASA 202 Statistics and Information Systems for Policy Evaluation
}

BOOK OF SHORT PAPERS

of the on-site conference

edited by

Bruno Bertaccini

Luigi Fabbris

Alessandra Petrucci

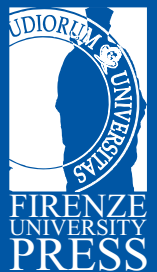


PROCEEDINGS E REPORT

ISSN 2704-601X (PRINT) - ISSN 2704-5846 (ONLINE)

-132 - 
Scientific Program Committee

Luigi Fabbris (co-chair) (University of Padua)

Alessandra Petrucci (co-chair) (SIS - University of Florence)

Luciana Annarumma (Assirm)

Fabio Bacchini (ISTAT)

Rossella Berni (University of Florence)

Bruno Bertaccini (University of Florence)

Luigi Biggeri (University of Florence)

Eugenio Brentari (University of Brescia)

Maurizio Carpita (University of Brescia)

Giulia Cavrini (Free University of Bolzano-Bozen)

Alessandro Celegato (AICQ-AISS, PSV Project Service and Value)

Giuliana Coccia (Alleanza Sviluppo Sostenibile ASviS)

Cristina Davino (Federico II University of Naples)

Adriano Decarli (University of Milan)

Loretta Degan (Galgano Group, Milan)

Tonio Di Battista (“G. D'Annunzio" University of Chieti and Pescara)

Enrico Di Bella (University of Genoa)

Angela Maria Digrandi (CNR)

Simone Di Zio ("G. D’Annunzio" University of Chieti and Pescara)

Guido Ferrari (University of Florence)

Benito Vittorio Frosini (Sacred Heart Catholic University of Milan)

Antonio Giusti (University of Florence)

Gabriella Grassia (Federico II University of Naples)

Salvatore Ingrassia (University of Catania)

Michele Lalla (University of Modena and Reggio Emilia)

Corrado Lagazio (University of Genoa)

Paolo Mariani (University of Milan-Bicocca)

Stefania Mignani (University of Bologna)

Francesco Palumbo (Federico II University of Naples)

Alfonso Piscitelli (Federico II University of Naples)

Giorgio Tassinari (University of Bologna)

Laura Trinchera (NEOMA Business School, FR)

Venera Tomaselli (University of Catania)

Domenico Vistocco (Federico II University of Naples)

Local Program Committee

Bruno Bertaccini (chair) (University of Florence)

Silvia Bacci (University of Florence)

Chiara Bocci (University of Florence)

Federico Crescenzi (University of Florence)

Maria Veronica Dorgali (University of Florence)

Carla Galluccio (University of Florence)

Antonio Giusti (University of Florence)

Alessandra Petrucci (University of Florence) 


\title{
ASA 2021 Statistics and Information Systems for Policy Evaluation
}

\author{
BOOK OF SHORT PAPERS \\ of the on-site conference
}

\author{
edited by \\ Bruno Bertaccini \\ Luigi Fabbris \\ Alessandra Petrucci
}




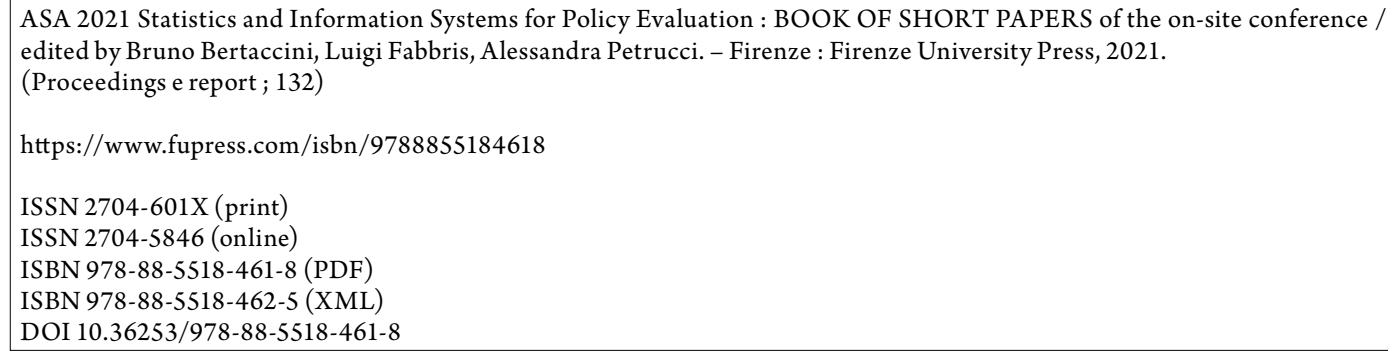

Cover graphic design: Lettera Meccanica SRLs

Front cover: (C) man64|123rf.com

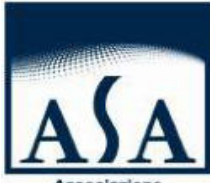

per la Statistica Applicat

\section{ASA 2021 On-site Conference on \\ STATISTICS AND INFORMATION SYSTEMS \\ FOR POLICY EVALUATION}

University of Florence, September 6 - 8, 2021

Bruno Bertaccini, Luigi Fabbris and Alessandra Petrucci

(Editors)

\section{Partners}
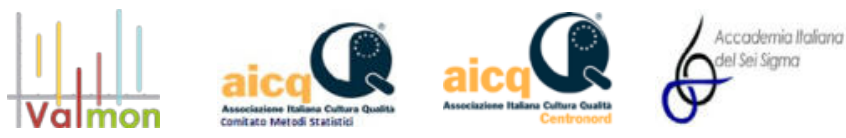

SASSIRM

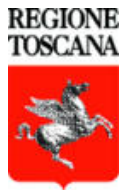

FUP Best Practice in Scholarly Publishing (DOI https://doi.org/10.36253/fup_best_practice)

All publications are submitted to an external refereeing process under the responsibility of the FUP Editorial Board and the Scientific Boards of the series. The works published are evaluated and approved by the Editorial Board of the publishing house, and must be compliant with the Peer review policy, the Open Access, Copyright and Licensing policy and the Publication Ethics and Complaint policy.

Firenze University Press Editorial Board

M. Garzaniti (Editor-in-Chief), M.E. Alberti, F. Vittorio Arrigoni, E. Castellani, F. Ciampi, D. D’Andrea, A. Dolfi, R. Ferrise, A. Lambertini, R. Lanfredini, D. Lippi, G. Mari, A. Mariani, P.M. Mariano, S. Marinai, R. Minuti, P. Nanni, A. Orlandi, I. Palchetti, A. Perulli, G. Pratesi, S. Scaramuzzi, I. Stolzi.

○ The online digital edition is published in Open Access on www.fupress.com.

Content license: except where otherwise noted, the present work is released under Creative Commons Attribution 4.0 International license (CC BY 4.0: http://creativecommons.org/licenses/by/4.0/legalcode). This license allows you to share any part of the work by any means and format, modify it for any purpose, including commercial, as long as appropriate credit is given to the author, any changes made to the work are indicated and a URL link is provided to the license.

Metadata license: all the metadata are released under the Public Domain Dedication license (CC0 1.0 Universal: https:// creativecommons.org/publicdomain/zero/1.0/legalcode).

(C) 2021 Author(s)

Published by Firenze University Press

Firenze University Press

Università degli Studi di Firenze

via Cittadella, 7, 50144 Firenze, Italy

www.fupress.com

This book is printed on acid-free paper

Printed in Italy 


\section{Table of contents}

Preface

SESSION

EVALUATION OF EDUCATIONAL SYSTEMS

Determinants of the transition to upper secondary school: differences between

immigrants and Italians

Patrizio Frederic, Michele Lalla

The top candidate is an intermediate one:

An analysis of online posts of Veneto industries

Luigi Fabbris

Psychometric properties of a new scale for measuring academic positive

psychological capital

Pasquale Anselmi, Daiana Colledani, Luigi Fabbris, Egidio Robusto, Manuela Scioni

Gender and Information and Communication Technologies interest: results from

PISA 2018

Mariangela Zenga

A structural equation model to measure logical competences

Silvia Bacci, Bruno Bertaccini, Riccardo Bruni, Federico Crescenzi,

Beatrice Donati

Clustering students according to their proficiency: a comparison between different approaches based on item response theory models

Rosa Fabbricatore, Francesco Palumbo

Sustainable Innovation: worldwide trends in the scientific production through a bibliometric study

Rosanna Cataldo, Corrado Crocetta, Maria Gabriella Grassia, Paolo Mazzocchi,

Antonella Rocca, Claudio Quintano

Personal weaknesses recognized by high school students in the North-West of Italy

Luigi Bollani

Emergency remote teaching: an explorative tool

Emma Zavarrone, Maria Gabriella Grassia, Rocco Mazza, Alessia Forciniti

Effects of an experimental online education support on lectures fruition and teaching effectiveness

Maria Cristiana Martini, Marco Furini, Giovanna Galli 
SESSION

DECISION MAKING

Measuring the effectiveness of COVID-19 containment policies in Italian

regions: are we doing enough?

Demetrio Panarello, Giorgio Tassinari

Motivation of basketball players: a random-effects logit model for the probability of winning

Silvia Bacci, Tijan Juraj Cvetković

Reducing inconsistency in AHP by combining Delphi and Nudge theory and network analysis of the judgements: an application to future scenarios

Simone Di Zio

Mapping and factoring the 2007 ATECO categories in regard to specialised human capital

Luigi Fabbris, Paolo Feltrin

Modelling the spatio-temporal dynamic of traffic flows with gravity models and mobile phone data

Maurizio Carpita, Rodolfo Metulini

The effectiveness of marketing tools in a consumer goods market in Italy during the Great Recession (2010-2015)

Giorgio Tassinari, Demetrio Panarello

The role of the extra-man play actions in elite water polo matches: which

elements lead to a good shot?

Alessandro Lubisco

Big data analysis and labour market: an analysis of Italian online job vacancies data

Francesca Giambona, Adham Khalawi, Lucia Buzzigoli, Laura Grassini,

Cristina Martelli

Sizing \& Allocation in Labour Market: business strategies and multivariate analysis

Andrea Marletta

Post-stratification as a tool for enhancing the predictive power of classification

methods

F.D. d'Ovidio, A.M. D'Uggento, R. Mancarella, E. Toma

A statistical information system in support of job policies orientation

Adham Kahlawi, Francesca Giambona, Lucia Buzzigoli, Laura Grassini,

Cristina Martelli

Linear regression pathmox segmentation tree: the case of visitors' satisfaction to attend a Spanish football match at the stadium

Cristina Davino, Giuseppe Lamberti

Exploring competitiveness and wellbeing in Italy

by spatial principal component analysis

Carlo Cusatelli, Massimiliano Giacalone, Eugenia Nissi

Total Process Error framework: an application to economic statistical registers 
SESSION

HEALTH AND WELL-BEING

Development of an innovative methodology to define patient-designed quality of

life: a new version of a wellknown concept in healthcare

Barbara Bartolini, Serena Bertoldi, Laura Benedan, Carlotta Galeone,

Paolo Mariani, Francesca Sofia, Mariangela Zenga

Measuring the impact of healthcare indicators on academic medical centers'

scientific production

161

Corrado Cuccurullo, Luca D'Aniello, Massimo Aria, Maria Spano

EGIPSS model for the evaluation of performance in healthcare

Pietro Renzi, Alberto Franci

Unsupervised spatial data mining for the development of future scenarios: a

Covid-19 application

Yuri Calleo, Simone Di Zio

Supporting decision-makers in healthcare domain. A comparative study of two interpretative proposals for Random Forests

Massimo Aria, Corrado Cuccurullo, Agostino Gnasso

Media and fake news: An analysis of citizens' attitudes toward misinformation in European countries

Mauro Ferrante, Anna Maria Parroco

Longitudinal profile of a set of biomarkers in predicting Covid-19 mortality

using joint models

Matteo Di Maso, Monica Ferraroni, Pasquale Ferrante, Serena Delbue,

Federico Ambrogi

Assessment of agricultural productivity change at country level: A stochastic frontier approach

Alessandro Magrini

Patient-generated evidence in Epidermolysis Bullosa (EB): Development of a questionnaire to assess the Quality of Life

Laura Benedan, May El Hachem, Carlotta Galeone, Paolo Mariani, Cinzia Pilo,

Gianluca Tadini

A Prospective Sustainability Indicator for Pension Systems

Fabrizio Culotta

Unemployment dynamics in Italy: a counterfactual analysis at Covid time

Illya Bakurov, Fabrizio Culotta

SESSION

TOURISM AND GASTRONOMY

Understanding the sensory characteristics of edible insects to promote

entomophagy: A projective sensory experience among consumers

Alfonso Piscitelli, Roberto Fasanelli, Elena Cuomo, Ida Galli

Experience, sensorial skills and personality qualifying a wine consumer as an expert

Luigi Fabbris, Alfonso Piscitelli

Prediction of wine sensorial quality: a classification problem 
Tourism of Italians in Italy through crisis and development: the last 15 years, region by region

Fabrizio Antolini, Antonio Giusti

Assessment of visitors' perceptions in protected areas through a model-based clustering

Annalina Sarra, Adelia Evangelista,Tonio Di Battista 


\section{Preface}

The Association for Applied Statistics (ASA) and the Department of Statistics, Computer Science, Applications DiSIA "Giuseppe Parenti" of the University of Florence, jointly with the partners AICQ-CN (Italian Association for Quality Culture North and Centre of Italy), AISS (Italian Academy for Six Sigma), ASSIRM (Italian Association for Marketing, Social and Opinion Research), Comune di Firenze (the Florence Municipality), SIS (the Italian Statistical Society), Regione Toscana (the Tuscany Region) and Valmon - Evaluation \& Monitoring Ltd, have organised a scientific conference titled "Statistics and Information Systems for Policy Evaluation", aimed at promoting new statistical methods and applications for the evaluation of policies.

Due to the health emergency caused by the COVID-19 pandemic, the Scientific and the Local Organizing Committees decided to reschedule the conference appointment in two different scientific events: an on-line Opening Conference held in February and March 2021 and a postponed on-site Conference held in September 2021.

This Book includes 40 peer-reviewed short papers discussed during the on-site Scientific Conference. This event was spread over 3 days and organized in thematic sessions; each session, led by a chair, collected works on the following homogeneous issues: "Evaluation Of Educational Systems", "Decision Making", "Health and Well-Being", "Tourism and Gastronomy". The papers published in this book are organized in those sessions.

On behalf of the Scientific Program Committee, we would like to thank the authors for submitting and presenting their interesting and inspiring works in the context of the evaluation of policies, the partners, the chairs, the discussants and the Local Organizing Committee. Finally, we are thankful to the members of the Scientific Committee for helping with the peer-reviewing process.

Florence (Italy), October 2021

Bruno Bertaccini, Luigi Fabbris, Alessandra Petrucci 


\title{
Personal weaknesses recognized by high school students in the North-West of Italy
}

\author{
Luigi Bollani
}

\section{Introduction}

This study is part of a project aimed at supporting the weaknesses of young people who are experiencing, or are at risk of reaching, NEET condition (Not in Education, Employment or Training; aged between 15 and 29 or 34, according to different definitions).

At present the entire project consists of three phases. The first, concluded in 2020 with the volume "From Neet to Need" (see also Bollani, Rota, 2018), presents the European statistical situation of the Neet phenomenon and its sociological implications; it includes an empirical study, based on thorough interviews with people in Neet condition intended to collect their life stories (Merril, West, 2012); the purpose is to classify them as to their internal and external needs, in order to suggest adequate support for intervention. The second phase, to be completed in 2021 with a second book, is the object of this study: it searches for harbingers of Neet status in the difficulties encountered during high school (which in Italy is divided into an initial two-year set and a subsequent three-year set); in fact, in general it is more simple and effective to tackle minor problems by a preventive approach, starting from school age. Of course students as such are not Neets and the anonymity required for a survey dealing with very personal issues does not allow a longitudinal study to be carried out on the same individuals. However, the construction of a comparison base referring to a generic population, relative to the incidence of certain states of weakness (or some of their combinations), will allow for a subsequent comparison with the incidence of the same difficulties in school age for those who find themselves in a Neet situation. The third phase, started in 2021, is about identifying good practices in order to grow Neets into working adults; the people selected to accompany the Neets in this process are now fully trained, while the first groups of Neets will be involved by the end of the year. The research group was identified among members of the InCreaSe Association (Innovation Creativity Settings; www.increasegroup.org), which boasts transversal research skills. Numerous local authorities are involved in the project, which is supported by Compagnia di San Paolo Foundation.

As to the specific object of this paper, the first signs of the extreme discomfort caused by Neet condition were sought by investigating signs of weakness in high school students in the Piedmont, Valle d'Aosta and Liguria regions. A survey questionnaire was administered to students, an operator being present in the classrooms, shortly before the start of the pandemic. Collected results will therefore be more directly linked to school activities "in presence", even if discontinuities in teaching methods and characteristics caused by the pandemic might have brought in alterations that will need to be monitored over time.

\section{Themes of investigation and subjects involved}

School transmits knowledge accumulated and elaborated by society over the centuries, allowing younger generations to experience social, cultural and territorial belonging and to be citizens of the society with its rights and duties.

The proposed survey is embedded in the context of training institutions challenged to cope with rapid change and face uncertainty about the impact of offered training courses on personal 
growth and access to work in the current context. The intention of the study is to highlight positive states of well-being, certainly present in a school context, but at the same time identify situations of discomfort among students which, if not adequately prevented, can develop in a harmful way. It was decided to address the issue from within the school itself, administrating questionnaires to students engaged in secondary education.

The topics of the survey, included in the questionnaire within specific sections, were:

- You and the school (role attributed to the school)

- The relationship with your school

- The relationship with your teachers

- The relationship with your schoolmates

- You and your future (for the three-year period only)

- The relationship with your family

- Personal and family data

Special attention was devoted to the field organization, with an operator present in each class during the survey in order to ensure correct presentation of the questionnaire and homogeneous assistance as well as sense of anonymity towards teachers during its compilation.

It should be mentioned that the Italian secondary education system is divided into an initial compulsory two-year period ("biennio" below) and a subsequent voluntary three-year period ("triennio"); it is also divided into a more academic (classical or scientific) school called "liceo", a technical school ("tecnico") and a vocational school ("professionale").

Students were selected following a multi-stage process, considering schools and classes as first and second level units and students as third level units. The first stage units, i.e. the schools, reflect different territorial situations, with several focuses in the three regions. In particular, for Piedmont distinctions were made according to size and location of the centres and among Turin city areas with different socio-economic patterns. The choice of second stage units, i.e. classes, allowed to reach, to a certain extent, an overall balance among different educational paths; finally, for third stage units, i.e. students, a complete survey of the students present in classrooms at the time of the survey was opted for. In this way, 14 schools (some classes for each) were surveyed, in line with the three Italian regions of interest. In Piedmont 10 schools are considered: three are in Turin city (see Torino1, 2 and 3 in table 1), two in the city belt (in the municipalities of Nichelino and Settimo Torinese), five in other areas of Piedmont (one in the municipality of Pinerolo, close to Turin, and four in different provinces). In Valle d'Aosta and Liguria, two schools were surveyed (see Aosta1 and 2 for Valle d'Aosta and two schools in the municipalities of Genova and Savona for Liguria). Globally, 931 students were surveyed, keeping a sufficient number for each type of educational path, as shown in table 1.

Table 1 - Number of students surveyed by education type and school area

\begin{tabular}{|c|c|c|c|c|c|c|c|c|c|}
\hline & $\begin{array}{l}\text { Biennio } \\
\text { Liceo }\end{array}$ & $\begin{array}{l}\text { Biennio } \\
\text { Professionale }\end{array}$ & $\begin{array}{l}\text { Biennio } \\
\text { Tecnico }\end{array}$ & $\begin{array}{l}\text { Subtotal for } \\
\text { Biennio }\end{array}$ & $\begin{array}{l}\text { Triennio } \\
\text { Liceo }\end{array}$ & $\begin{array}{l}\text { Triennio } \\
\text { Professionale }\end{array}$ & $\begin{array}{l}\text { Triennio } \\
\text { Tecnico }\end{array}$ & $\begin{array}{l}\text { Subtotal for } \\
\text { Triennio }\end{array}$ & Total \\
\hline Torinol & 17 & & & 17 & 32 & & & 32 & 49 \\
\hline Torino 2 & & & 20 & 20 & & & 24 & 24 & 44 \\
\hline Torino3 & & 16 & & 16 & & 16 & & 16 & 32 \\
\hline Nichelino & 14 & & 34 & 48 & 37 & & 15 & 52 & 100 \\
\hline SettimoT.se & & 24 & 16 & 40 & & 33 & 12 & 45 & 85 \\
\hline Pinerolo & & 18 & & 18 & & & 16 & 16 & 34 \\
\hline Asti & & & 40 & 40 & & & 18 & 18 & 58 \\
\hline Cuneo & & 43 & 25 & 68 & 37 & 19 & 23 & 79 & 147 \\
\hline Novara & 45 & & & 45 & 24 & & & 24 & 69 \\
\hline Vercelli & & 15 & & 15 & & 39 & & 39 & 54 \\
\hline Aosta1 & & & 32 & 32 & & & 35 & 35 & 67 \\
\hline Aosta2 & & 37 & & 37 & & 32 & & 32 & 69 \\
\hline Genova & & 17 & & 17 & & & 27 & 27 & 44 \\
\hline Savona & & & 58 & 58 & & & 21 & 21 & 79 \\
\hline Total & 76 & 170 & 225 & 471 & 130 & 139 & 191 & 460 & 931 \\
\hline
\end{tabular}




\section{Growth of weakness as an accumulation process}

A first research objective concerns how weakness is formed and how it can grow. One possibility that also seems to emerge from life stories is that there is an accumulation phenomenon. A perhaps tolerable weakness emerging for a particular aspect of life in school age may be aggravated by a second circumstance of discomfort, and so on, with the consequence of reaching a very intense state of discomfort due to a sum of causes, each of which is not particularly relevant.

In this perspective, the approach used for this paper consists in considering the key questions of each section of the questionnaire, which, each in view of a specific aspect, detected a condition of well-being or weakness of the answering student. The number of difficult situations encountered for each student was then added; this sum enabled to consider further degrees of individual difficulty.

In particular, ten questions were examined, two for each section of the questionnaire; they are presented below; labels used in figures and the percentage of students in a state of weakness (see ending "_yes") for each of them appear in brackets.

As regards the first part of the questionnaire, related to the role students attribute to the school and the relationship they have with it (first two sections), the selected questions were on:

- the importance of school in one's life (Life_yes: 4.40\%)

- the school's ability to foster personal growth (Growth_yes: 13.43\%)

- I thought about changing school (Change_yes: 47.91\%)

- prolonged absences (Absences_yes: $30.08 \%$ )

An aspect fundamental in determining the categories of students most in difficulty certainly is the one concerning the relationship with classmates, which if problematic can lead to important episodes of exclusion and marginalization; thus the chosen questions were whether they:

- were teased or isolated by school friends (Isolated_yes: $24.92 \%$ )

- go out with classmates outside school hours (Outside_yes: 33.30\%)

Other elements taken into consideration are the average grade and the relationship with their teachers; the selected questions concerned:

- whether they ask teachers questions when they do not understand (Questions_yes: 39.74\%)

- which was their average grade in the last term (Grades_yes: 48.44\%)

Finally, two questions were chosen from the section about the relationship with one's family, i.e. whether:

- students feel supported by their family (Support_yes: 16.33\%)

- they have confidence with any adults (Confide_yes: $21.27 \%$ )

The answers to each of these ten questions were coded in terms of presence or absence of weakness; the resulting synthetic variable indicates the amount of weakness situations, which can vary from zero (absence of weakness) to ten (maximum weakness intensity) for each answering student. The frequency distributions of this variable, called "intensity of weakness", for all respondents and for those living in different territorial areas of interest for the survey, are presented in figure 1.

The shapes of the frequency distributions shown in the figure are very similar, although Turin belt and Liguria display the highest average levels of weakness intensity (3.0 and 3.1) and city of Turin and belt of Turin show the highest variability (standard deviation 2.0 and 1.9).

In all cases, at higher degrees of weakness frequencies progressively decrease. Referring to a more stable condition, intensity of weakness is also measured more synthetically as follows, assuming to set only three qualitative degrees of weakness: students with intensity of weakness 0 and 1 are categorized as students "without weakness" (or nearly so), those with scores 2 and 3 are considered to have "lower weakness", while students with a score higher than 3 fall into the "greater weakness" category. The subdivision into bands respects the subdivision into tertiles, considering the variable starting from the most disadvantaged in the general total column 
(obtaining following frequencies: greater weakness 33.94\%; lower weakness $39.53 \%$ and without weakness $26.53 \%$ ).

Figure 1 - Frequency distributions of the intensity of weakness (0-10)

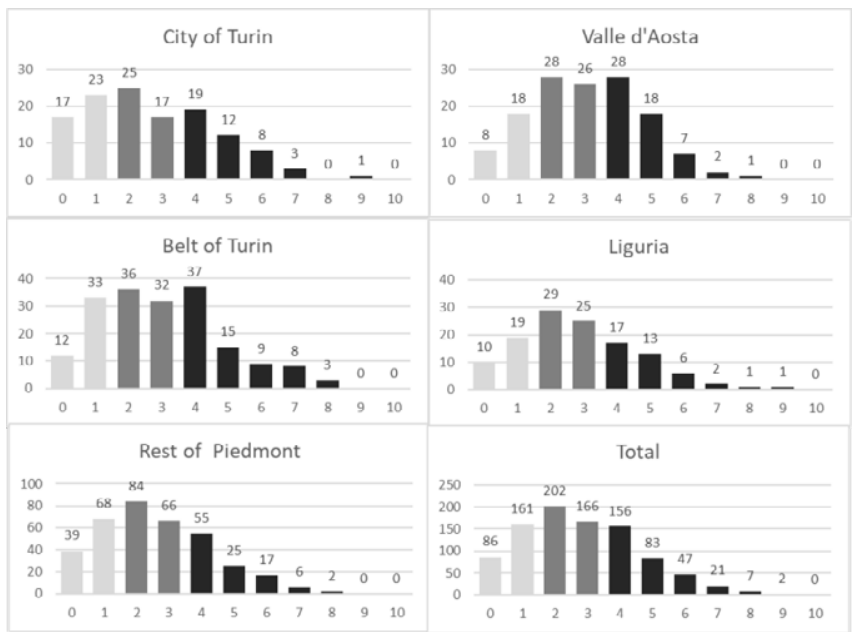

In order to check the usefulness of the considered variable empirically, as to the degree of weakness, a multiple correspondence analysis (MCA) was performed on the binary codified ten variables used for its construction; the intensity of weakness, as both ten level and three synthetic level variables, are maintained as supplementary. The MCA map is shown in Figure 2; software R and FactoMineR package were used for the analysis (Escofier, Pagès, 2008).

Figure 2 - Relationships among the ten main variables of the questionnaire (active variables are shown in the left box, while supplementary ones, relating to the intensity of weakness, are shown in the two boxes on the right)
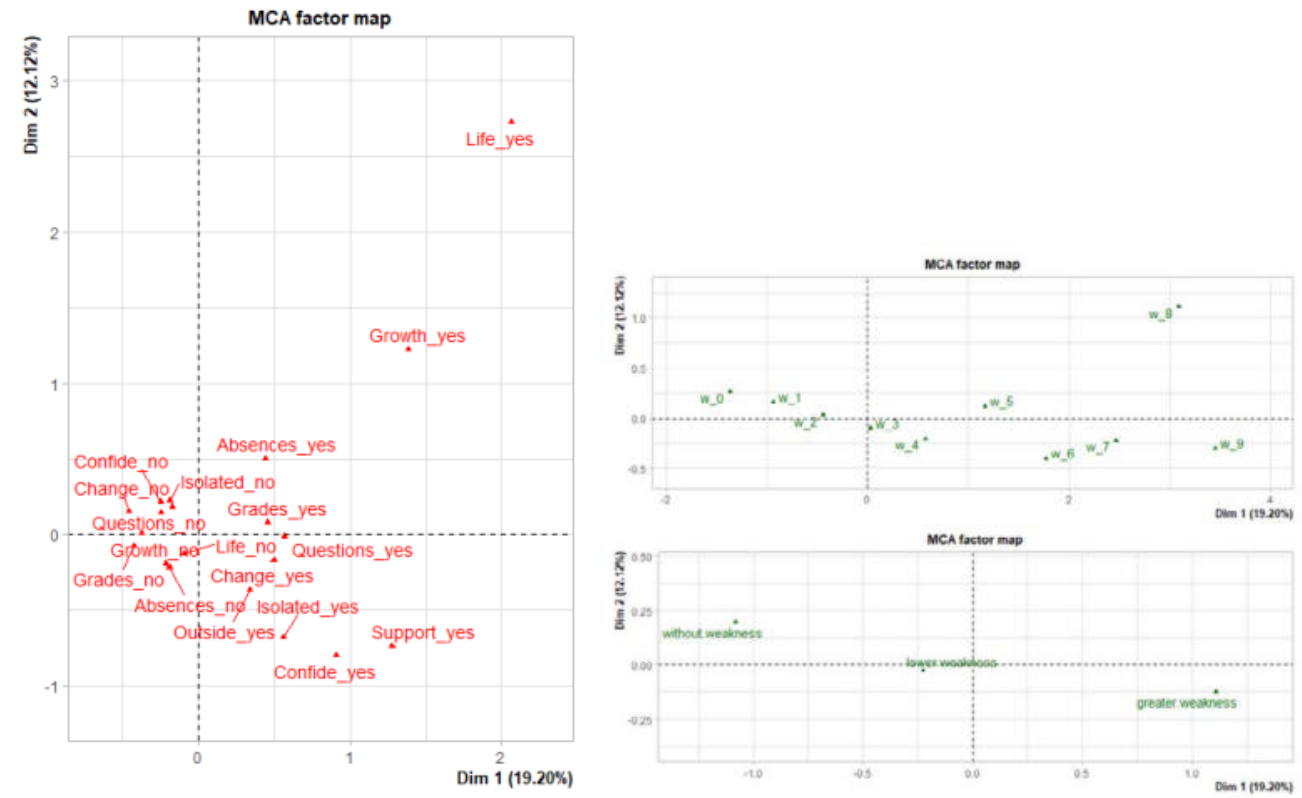
Note: the MCA, given its coding scheme, underestimates the percentage of inertia explained by the first factorial dimensions (Abdi, Valentin, 2007). In literature, some methods of reevaluation of variances explained by first factorial dimensions are indicated to overcome this drawback (Benzécri, 1973; Greenacre, 2017). Using Greenacre's method (more parsimonious), we obtain a variance percentage of $74.65 \%$ for the first dimension and of $3.97 \%$ for the second (overall, therefore, the first factorial plan would explain the variance of $78.62 \%$, which seems satisfactory; R software and in particular the ca package was used for this re-evaluation, as in Nenadic, Greenacre, 2007).

It can be observed that the intensity of weakness may be used as a good synthesis of the ten variables, as it displays quite homogeneous levels, growing from left to right of the graph and substantially following the first axis of the map. This is congruent with the presence of almost all "no" (absence of weakness) statements for almost all variables on the left of the map, while the "_yes" (presence of weakness) statements are on the right.

It should also be noted that negative responses to the fact that school is useful for one's life and for personal growth, corresponding to a state of weakness visible in the map at the top right in an eccentric position (Life_yes and Growth_yes), are generally less recurrent than other types of weakness (4.40\% for Life_yes and $13.43 \%$ for Growth_yes).

\section{Living conditions that can facilitate weakness}

Considering Figure 2 again, the most important reading direction is - as already shown - from the far left (absence of weakness) to the far right (greater weakness). However, a second useful piece of information can be found using the bottom-up dimension, especially in the quadrants to the right of the graph where the points are vertically more dispersed and can provide information on the type of discomfort experienced. In fact, staying on the right, towards the top there are the already known negative answers on the importance of school for one's life and growth and also situations of prolonged absence (Absences_yes): this could suggest a difficulty deriving from lack of motivation and escape. On the downside, however, there is a lack of support and attention from adults (Confide_yes; Support_yes), as well as isolation at school and outside peer groups (Isolated_yes, Outside_yes).

Figure 3 - Supplementary variables in the same plane as Figure 2.

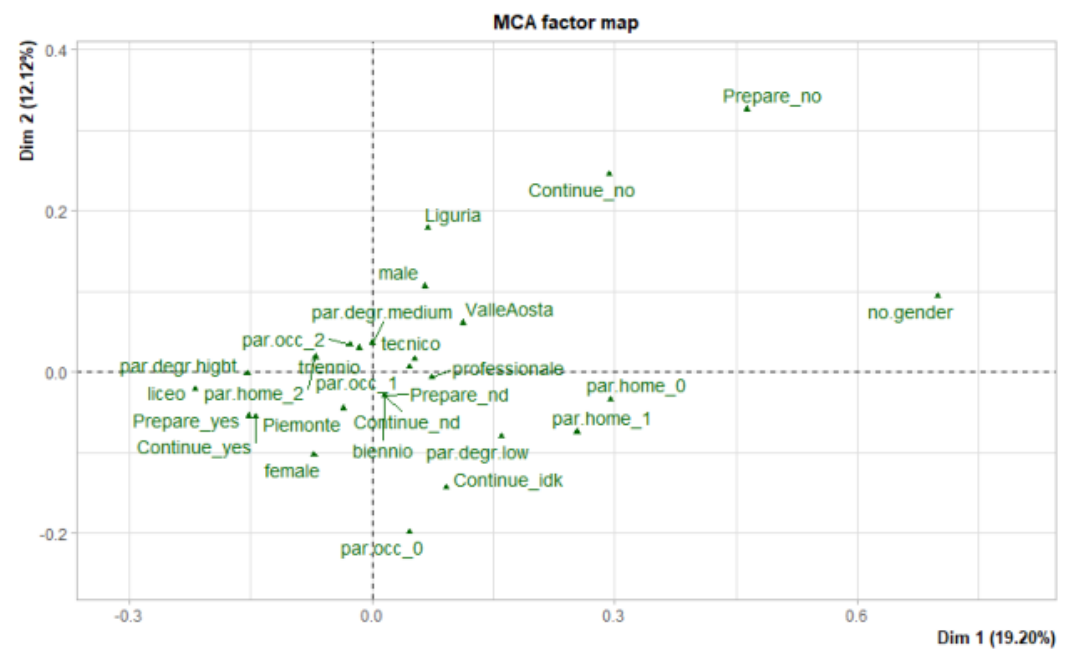

Figure 3 also shows, on the same factorial plane as Figure 2, some characteristics of the surveyed students.

On the left side of the map, where difficulty is generally low, we note the simultaneous greater 
presence of both parents in the family unit of cohabitation (par. home_2), a high parental qualification (at least for one of the two parents; par. degr. high), "liceo" enrolment; for students of the second three-year period (who were asked more questions) also the conviction that school prepares for the future and they will to continue studying.

Compared to "liceo" students, those from other paths ("professionale", "tecnico") generally show more weakness. Females appear to be in a better position than males. Piedmontese schools seem to be in a better position than those of Valle d'Aosta or Liguria.

Looking at the top right of the map, students of the second three-year period, who do not think school prepares for the future (Prepare_no) and do not want to continue studying (Continue_no) are in the same position as those already discussed with lack of motivation and orientation to escape in Figure 2.

On the bottom right, which is the already discussed area with more students unsupported by adults and isolated by peers, Figure 3 adds the information concerning greater presence in this area of parents with low qualification (par. degr. low) and difficulty of presence of both parents in the family unit of cohabitation (par. home_0 or par. home_1).

\section{Conclusions}

In this study, which considers secondary education institutions from the inside by a survey conducted on students, a transversal look at the various sections of the survey questionnaire was maintained to highlight one of the key aspects of the research, aimed at observing situations of well-being, but also of progressive weakness of the students themselves.

The focus is on observing in the sense of describing and therefore favouring a reflection on causes determining weakness: a method to place surveyed students in a scale polarized between well-being on the one hand and extreme discomfort on the other was proposed; subsequently it was shown how some characteristics (to be explored as possible motivations), derived above all from the school and parenting context, can accompany the different situations of intensity of individual weakness.

Furthermore, in the last three-year school period, attention was devoted to how one's "feeling" within the school context can influence the desire for a future perspective for oneself and how it can influence choices.

\section{References}

Abdi, H.; Valentin, D. (2007). Multiple correspondence analysis, ed. N. Salkind, Encyclopedia of Measurement and Statistics, Sage Publications, Thousand Oaks, (CA), 95, pp. 116-128.

AA.VV. (2020). From Neet to Need. Il cortocircuito sociale dei giovani che non studiano e non lavorano, eds. G. Lazzarini, L. Bollani, F. S. Rota, M. Santagati. Innovation Creativity Settings, Franco Angeli, Torino.

Benzécri, J.P. (1973). L'Analyse des Données. Dunod, Paris.

Bollani L., Rota F.S. (2018). Orientamenti per una comprensione ecosistemica dei NEET e conseguenti politiche di sostegno, EyesReg, 8,2.

Escofier, B., Pagès, J. (2008). Analyses Factorielles Simples et Multiples: Objectifs, Méthodes et Interprétation; Dunod, Paris.

Greenacre, M. (2017). Correspondence Analysis in Practice; Chapman and Hall, New York.

Merril B., West L. (2012). Metodi biografici per la ricerca sociale, Apogeo.

Nenadic, O., Greenacre, M. (2007). Correspondence analysis in R, with two-and threedimensional graphics: The ca package. Journal of Statistical Software, 20(3), pp. 1-13. 
his book includes 40 peer-reviewed short papers submitted to the Scientific Conference titled Statistics and Information Systems for Policy Evaluation, aimed at promoting new statistical methods and applications for the evaluation of policies and organized by the Association for Applied Statistics (ASA) and the Dept. of Statistics, Computer Science, Applications DiSIA "G. Parenti" of the University of Florence, jointly with the partners AICQ (Italian Association for Quality Culture), AICQ-CN (Italian Association for Quality Culture North and Centre of Italy), AISS (Italian Academy for Six Sigma), ASSIRM (Italian Association for Marketing, Social and Opinion Research), Comune di Firenze, the SIS - Italian Statistical Society, Regione Toscana and Valmon - Evaluation \& Monitoring.

Bruno Bertaccini is Associate Professor of Statistics at the "G. Parenti" Department of Statistics, Computer Science and Applications of the University of Florence. After earning his PhD in Applied Statistics, he became an expert in the effectiveness assessment of public policies, with particular attention to the evaluation of the quality of higher education and academic policies.

Luigi Fabbris is a freelance researcher in the field of statistics and social science; President of the ASA, (Italian) Association for Applied Statistics; formerly Professor of Social Statistics at the University of Padua; he has authored or co-authored more than 400 papers or books.

Alessandra Petrucci is Professor of Social Statistics and she holds a PhD in Applied Statistics. Her research interests include survey sampling methods, spatial statistics, multivariate statistical analysis applied to social and environmental issues. She is the author and co-author of numerous scientific papers published in national and international journals, and she has been a member of research projects and scientific committees for several national and international conferences. 